\title{
The Protective Role of School Adjustment Between Risky Neighborhood Environment and Adolescent Drinking and Smoking
}

\author{
Shinah Kim, Yoonsun Han \\ Department of Child Psychology and Education, Sungkyunkwan University, Seoul, Korea \\ 지역사회 유해환경과 청소년의 음주흡연 경험과의 관계에서 \\ 학교적응의 보호 작용 \\ 김신아, 한윤선 \\ 성균관대학교 아동청소년학과
}

Objective: To prevent adolescent drinking and smoking, this study proposed a strategy based on the ecological perspective.

Methods: The study applied multilevel moderated logistic regression analysis on nationally representative individual-level (2,046 9th grade adolescents) and neighborhood-level (92 geographic areas) data.

Results: There was a positive association between risky neighborhood environments (e.g., rate of smoking, drinking, and presence of saloon/bars accommodation) and rates of adolescent drinking and smoking. Furthermore, the interplay between risky neighborhood environments and school adjustment pointed to a possible protective effect of a high level of school adjustment in predicting smoking and drinking among adolescents.

Conclusion: Findings highlighted the importance of considering multiple neighborhood social contexts surrounding adolescents to understand their risky behavior. Furthermore, positive intervention strategies that focus on adolescents' positive development within the school domain may act to protect adolescents from harmful neighborhood environments.

Keywords: Risky neighborhood environment, School adjustment, Alcohol drinking, Cigarette smoking, Adolescent

\section{서론}

1990년대 이후 청소년의 음주 및 흡연의 저연령화는 심각 한 사회 문제로 대두되어 왔다(Hong, Lee, Grogan-Kaylor, \& Huang 2011). 1997년에 청소년보호법이 제정되고 2000년대 들어 청소년 음주 및 흡연은 감소 추세를 보이고 있지만, 2013 년 현재 청소년 음주율(최근 30 일 동안 1 잔 이상 술을 마신 적

Corresponding Author: Yoonsun Han, Department of Child Psychology and Education, Sungkyunkwan University, 25-2, Sungkyunkwan-ro, Jongro-gu, Seoul 110-745, Korea

E-mail: yoonsunhan@skku.edu
이 있는 사람)과 흡연율(최근 30 일 동안 1 일 이상 흡연한 사 람)은 각각 $16.3 \%$ 와 $9.7 \%$ 로 여전히 높은 편이다(Korea Centers of Disease Control and Prevention, 2014). 또한 음주 및 흡연을 처음 경험한 평균 연령이 12-13세로 저연령화 되는 추세이며 (Ministry of Gender Equality \& Family [MOGEF], 2014), 음주 와 흡연을 일찍 시작한 청소년들이 성인기까지도 지속되는 경 우가 보고되고 있다(Kim \& Jeong, 2010). 최근에는 비록 법제

(C)The Korean Association of Child Studies

This is an Open Access article distributed under the terms of the Creative Commons Attribution Non-Commercial License (http:// creativecommons.org/licenses/by-nc/4.0) which permits unrestricted noncommercial use, distribution, and reproduction in any medium, provided the original work is properly cited. 
사법위원회를 통과하지 못했지만, 청소년 음주행위에 대한 고 조된 사회적 우려로 청소년에게 영향력이 높은 연예인, 운동 선수 등 만 24 세 이하의 젊은 유명인의 주류광고 출연을 금지 하는 일명 '아이유법'이 발의되어 이슈가 되기도 하였다(Jung, 2015).

청소년의 특정 행동은 상호의존적 요인들의 복잡한 작용 으로 인해 발생하며, 성인기의 해로운 행동으로 이어질 가능 성이 높기 때문에 음주 및 흡연과 같은 문제행동에 대한 사회 적 관심이 더 필요하다(Babbin, Velicer, Paiva, Brick, \& Redding, 2015; Rhee, Yun, \& Khang, 2007). Bronfenbrenner (1979)의 생 태학이론에 따르면, 개인의 행동은 개인과 주변 환경과의 상 호작용을 통해 형성된다. 즉, 개인을 둘러싼 생태체계들이 서 로 위계적으로 내포(nested)되어 있어 개인의 행동발달을 이해 하기 위해서는 가족.학교.지역사회 등 다양한 사회 환경들을 고려해야 한다는 것이다.

이에 청소년 문제행동을 이해하기 위한 지역사회 유해환경 의 고찰은 중요하다. 그 이유로 첫째, 청소년기라는 발달적 특 성 때문이다. 청소년기는 지역사회와의 접촉이 증가하는 시기 로 아동기에 비해 부모로부터 독립을 지향하고, 가정의 울타 리에서 벗어나 또래와 어울리며 지역사회 유해환경에 대한 노 출이 증가할 수 있다(Aber, Gephart, Brooks-Gunn, \& Connell, 1997). 둘째, 현대 사회의 특성 때문이다. 현대 사회는 문화적 개방화의 추세로 유해업체의 종류와 유형이 다양해지고 유해 업소에 대한 청소년의 접근이 수월해졌다(Kim \& Cha, 2007). 이 때문에 청소년 문제행동을 이해하기 위해서는 지역 환경, 특히 유해환경에 대한 이해가 필수적이다.

특별히 '유해'의 사전적 의미는 '해로움'이다. 즉, '유해환경' 이란 청소년에게 해로운 환경이라 할 수 있다 $(\mathrm{Kim}, \mathrm{Ju}, \& \mathrm{Lim}$, 2008). 그러나 해로움을 지닌 환경의 유무를 판단하는 기준이 나 해로움의 정도를 규명하기 위한 청소년 유해환경에 대한 정의를 학자마다 다양하게 제시하고 있다. 본 연구에서는 유 해환경을 Lee (1996)가 정리한 “청소년의 정상적인 성장을 직 접적으로 저해하는 미시적 환경뿐만 아니라 청소년 문제행동 유발 가능성이 높은 거시적 환경을 포괄”하는 종합적 개념으 로 정의한다. 즉, 청소년의 건전한 심신발달에 직접적인 해를 끼치는 환경요소와 청소년의 위해행동 촉발 가능성을 높이는 환경적 특성, 장소 및 매체 등을 유해환경이라 지칭한다. 이를 기반으로 본 연구에서는 청소년 음주 및 흡연행동에 영향을 미치는 유해환경으로써 업소환경을 중심으로 살펴보고자 하 였다.

유해업소는 두 가지 환경적 특성으로 분류가 가능하다. 첫
째, 업소에서 제공되는 서비스가 직접적으로 청소년에게 유해 한 경우, 둘째, 특정 업소와의 접촉이 간접적으로 청소년의 위 해행동으로 이어질 가능성이 높은 경우이다(Kim et al., 2008). 전자는 단란주점 및 유흥업소 등 청소년보호법(제2조 5항)에 서 구분하고 있는 청소년 출입·고용 금지업소를 가리킨다. 이 곳에서 제공되는 물품과 서비스는 청소년에게 직접적으로 해 롭다 판단되기 때문에 유해환경이라 지칭한다. 후자의 경우, 업소의 출입 및 고용이 위해행동 유발 개연성을 높여주는 장 소를 가리킨다. 이러한 유해환경은 만화방, 전자오락실, $\mathrm{PC}$ 방, 노래방, 룸카페, 비디오방, $\mathrm{DVD}$ 방과 같은 오락성 업소로 주 류판매 및 성매매 등의 불법운영을 통해 청소년의 음주, 흡연, 성관계 등을 묵인, 유발, 심화시킬 가능성이 높은 곳이다.

청소년유해업소의 유해성을 청소년 및 교사 등에게 설문조 사뿐만 아니라 심층면접방법을 사용하여 실증적으로 파악한 연구에서도 법적으로 정의된 청소년유해업소는 청소년에게 해로운 '직접적·간접적인 유해요인을 보유하고 있는 시설’로 재확인되었다(Kim \& Yoo, 2006). 편의점, 오락실, 카페와 같 은 잠재적 유해시설을 비롯하여 청소년 출입이 금지된 술집/ 유흥주점, 여관 등에서도 청소년의 유해접촉 경험이 확인됨으 로써 이들 청소년 유해시설의 실질적인 유해성이 확인되었다 (Yoo, 2007). 특히 Yoo (2007)의 연구에서는 잠재적 유해시설에 비해 출입이 엄격히 제한되어 있는 술집·유흥주점에서 청소 년들의 술·담배와 같은 유해물질에 대한 접촉비율이 높았다. 이와 같은 행정적·사법적 기준과 경험적 연구를 근거로(Han $\& \mathrm{Kim}, 2012)$, 본 연구에서는 업소환경을 청소년 유해환경으 로 제시하였다.

특별히 본 연구에서는 공공 기관이나 유해업소 및 업주들 의 책임 전가에 중점을 두는 제도적 접근에만 치중하기보다 유해환경의 청소년 문제행동에 대한 영향을 완화 시켜줄 수 있는 보호요인을 함께 모색하는 방안을 제안하고자 한다. 유 해업소와 같은 지역사회 환경은 청소년들의 심리.행동 발달 에 부정적 요인으로 작용하지만, 반드시 모든 청소년들이 같 은 수준의 악영향을 받는 것은 아니다(Han \& Kim, 2012). 같 은 지역에 거주하며 같은 유해환경에 노출되고 접촉할지라도 주위 환경에 더 민감한 청소년과 그렇지 않은 청소년이 있기 때문이다. 이 점은 유해환경의 직접적인 개선 및 위험요인의 제거뿐만 아니라, 보호요인의 활성화를 통해 청소년의 적응을 향상시키는 방법도 함께 추구하는 것이 중요함을 시사한다.

사회통제이론(social control theory)에 따르면 가정, 또래, 학교, 지역사회와의 강한 유대관계는 외적 보호요인으로써 주변 유해환경의 부정적 영향으로부터 청소년을 보호한다 
(Erickson, Crosnoe, \& Dornbusch, 2000). 개인과 주변 환경과의 결속이 강할수록 청소년들은 문제행동을 하지 않게 되며, 반 면 결속이 약해질수록 문제행동 확률이 높다는 것이다. 따라 서 유해환경과 접촉이 많은 곳에 거주하는 청소년이라도 다른 생태학적 환경내의 특정 요인과 유대가 강하다면 유해환경의 악영향을 상쇄시킬 수 있다.

학교는 청소년들이 지역사회 유해환경으로부터 받는 영 향을 상쇄시켜 줄 수 있는 보호요인이다. 청소년들이 사회적 유대를 맺을 수 있는 대표적인 환경이자, 적응의 지표로(Lee, $2005)$ 청소년에게 직접적인 영향을 미치기 때문이다. 선행연 구에서도 다양한 청소년 문제행동에 대한 보호요인으로 학 교를 제안하고 있다(Deković, 1999; Han, 2008; Han, Kim, \& $\mathrm{Ma}, 2015$; Lazzeri et al., 2014; Lee \& Lee, 2008). 즉, 학교는 알 코올 및 약물사용과 같은 청소년 위험행동의 보호요인으로 써(Hawkins, Catalano, \& Miller, 1992), 청소년들이 학교로부 터 지지를 받고 긍정적인 또래관계, 학업성취 및 학습에 대한 동기를 가질수록 외현화 문제는 감소한다(Deković, 1999). 또 한 청소년이 자신에 대한 교사와 학교의 관심이 높다고 지각 할수록 음주비율이 낮다는 보고도 있다(Kim \& Kim, 2013). 결 국, 청소년이 교사 및 학교와 유대관계를 맺고, 학교활동에 적 극적으로 참여하며 규칙을 수용함으로써 긍정적인 적응을 한 다면, 지역사회 유해환경이 청소년에게 미치는 영향은 감소할 것이다.

지역단위의 사회환경이 개인 삶의 질에 미치는 영향에 대 한 연구가 외국에서는 1990 년대 후반부터 활발히 진행되어 왔다(Sampson, Morenoff, \& Gannon-Rowley 2002). 생태체계이 론에 근거하여 미시체계인 개인의 행동발달을 연구하는데 있 어 거시체계인 지역단위 효과의 중요성을 강조하였다. 개인 과 가장 인접한 사회환경은 가족이지만, 가족 역시 지역사회 에 위계적으로 내포되어 있기 때문에 포괄적인 지역사회 효과 를 확인하는 연구가 증가하였다. 이에 반해, 국내 대부분의 선 행연구는 청소년의 행동발달에 영향을 주는 요인으로 거시적 지역 환경 보다는 미시적 개인 또는 가정요인에 집중해 왔다 (Chung \& Joung, 2014; Hwang, 2010; Min, 2014; Shin \& Jang, 2013). 물론, 거시적 환경이 청소년 제반 행동영역에 미치는 효과에 대한 선행연구가 부재한 것은 아니지만, 다음과 같은 한계점을 가진다. 첫째, 청소년 유해환경이 포괄적인 의미로 사용되고 있다. MOGEF (2014)에서는 "청소년에게 유해한 영 향을 미칠 가능성이 있는 사회환경 전반”이라고 한다. 하지 만, 실제로 유해환경의 종류는 다양하고 따라서 그 해로움이 청소년에게 미치는 경로 및 과정 또한 다양하다( $\mathrm{Han} \& \mathrm{Kim}$,
2012). 둘째, 유해환경에 대한 기존 학술논문이나 정책보고서 들은 유해환경이 청소년 위해행동에 미치는 악영향에만 집중 하는 경향이 있다. 또한 개인요인을 통제한 상태에서 지역사 회의 구조적 환경요인이 청소년 문제행동과 어떤 개연성이 있 는지에 대한 선행연구가 대부분이다(Kim, 2009; Yun, 2010). 이러한 연구들은 개인을 둘러싼 거시적 지역 환경 또한 청소 년의 행동발달을 좌우하는 생태학적관점을 반영한다는 점에 서 중요하지만, 거시체계가 개인의 행동에 영향을 미친다는 결론 도출에 그치기 때문에 유해환경의 악영향이 검증되더라 도 그 유해환경을 없애거나 변화를 시도하기란 어려울 수 있 다. 따라서 단순히 유해환경의 제거나 개선에만 의존하기보 다, 청소년 위험행동 발생 가능성 줄이고 유해환경의 악영향 을 상쇄 시켜줄 보호요인 탐색을 병행하는 것이 필수적이다 (Han \& Kim, 2012).

오늘날 청소년 음주 및 흡연과 같은 위해행동이 심각한 사 회현상인 가운데, 본 연구에서는 청소년 위험행동의 발생 가 능성을 줄이고 유해환경의 부정적 영향을 상쇄시켜 줄 보호요 인을 통한 개입 방안을 제시하고자 한다. 이를 위한 연구문제 는 다음과 같다.

\section{연구문제 1}

청소년의 학교적응은 지역사회 유해환경이 청소년 음주에 미 치는 효과에 보호요인으로 작용하는가?

\section{연구문제 2}

청소년의 학교적응은 지역사회 유해환경이 청소년 흡연에 미 치는 효과에 보호요인으로 작용하는가?

\section{연구방법}

본 연구는 한국아동·청소년패널조사와 시·군·구 단위의 지역 사회 자료 두 가지를 병합하여 사용하였다. 통합된 자료를 활 용하여 지역사회 유해환경과 청소년의 음주 및 흡연 행동간 관계를 파악하고, 청소년들의 학교적응이 보호요인으로 작용 하는지 분석할 것이다. 분석에 이용할 자료의 구체적 내용은 다음과 같다.

\section{1. 연구대상}

한국청소년정책연구원에서 실시한 '한국아동청소년패널조 
사(Korean Children and Youth Panel Survey)'는 층화다단집락추 출법으로 표집된 초1, 초4, 중1의 3개 패널을 대상으로 2010년 부터 2016년까지 7년간 반복, 추적 조사하는 단기종단패널 조 사로서 전국적인 대표성을 지닌다. 또한 시·군·구 단위에 거 주하는 학생들의 위치와 소속 학교에 대한 위치정보가 제공 되어 있어 시·군.구 단위로 발행되는 지방자치단체 통계자료 와 병합이 가능하여 지역사회의 유해환경이 청소년에게 미치 는 영향에 대한 연구가 용이하다(Kang $\&$ Nho, 2012). 본 연구 에서는 중1패널의 3차년도(2012) 데이터를 사용하였다. 청소 년기는 초기, 중기, 후기 각 시기마다 판단력, 의사결정, 자극 추구 등의 인지발달에 있어 차이가 있다(Steinberg, 2005). 또한 음주, 흡연과 같은 지위비행에 영향을 미치는 환경적 요인들 도 각 시기별로 다르다(Hwang, 2012). 본 연구에서 청소년 중 기에 해당하는 중학교 3학년을 대상으로 한 이론적 이유는 이 시기(만14-15세) 청소년들에게 강한 자의식, 불멸의식, 대범 함 등의 특성이 가장 두드러지게 나타나고 한편으로는 불안정 한 자아가 표출되기 때문이다. 특히 정서, 인지, 행동간 발달속 도의 차이로 환경에 대한 취약성이 높아져(Steinberg, 2005), 이 전에 비해 지역사회 유해환경과 접할 기회가 급증하는 이 시 기 청소년들은 유해환경의 부정적 영향에 가장 취약하게 된다 (Aber et al., 1997). 청소년의 음주 및 흡연행위의 영향요인분석 에 관한 연구에서도 초기에는 가정 및 개인요인이, 중기 및 후 기(특히 중기)에는 사회환경적 요인이 강력한 요인으로 나타 나(Hwang, 2012) 중기 청소년을 대상으로 유해환경에 대한 분 석의 필요성을 제시하였다.
최종 분석대상은 92개 지역(시·군·구)에 위치한 학교에 재 학 중인 총 2,046 명의 청소년이고, 각 지역 당 청소년은 평균 22.2명이다. 분석대상의 인구사회학적 특성과 주요변수에 대 한 빈도 및 기술통계는 Table 1 과 같다.

\section{2. 측정변수}

1) 독립변수: 지역사회 유해환경(숙박업소, 유흥업소, 음주율, 흡연율)

유해업소에 대한 정보는 2011년도 지방자치단체 통계자료를 사용하였다. 지방자치단체에서는 인구, 경제, 사회, 교육, 문화 등의 분야에 대한 시·군.구 단위의 정보를 제공하고 있다. 본 연구에서는 통계청의 개별 지방자치단체 통계자료(e-지방지 표)에 시·군·구 단위로 정리되어 있는 다양한 유해환경 중 숙 박업소(호텔업소 수, 여관업소 수, 기타 숙박업소 수를 합산) 에 관한 정보와, 유흥업소(단란주점업소 수, 일반 유흥주점업 소 수, 무도 유흥주점업소 수, 기타 주점업소 수를 합산), 그리 고 지역 음주율 및 흡연율에 관한 정보를 사용하였다. 따라서 유해환경은 ‘숙박업소'와 ‘유흥업소' ‘음주율', ‘흡연율' 4가지 차원으로 구분되며 각각의 정의는 다음과 같다.

(1) 숙박업소: 해당지역 총 인구수에 대한 숙박업소의 천분율 (\%)

(2) 유흥업소: 해당지역 총 인구수에 대한 유흥주점과 단란주 점 수의 천분율(\%o)

Table 1

Descriptive Summary of Variables

\begin{tabular}{|c|c|c|c|}
\hline Variable & $M(S D)$ & Min & $\operatorname{Max}$ \\
\hline \multicolumn{4}{|l|}{ Student variable (Level $1, N=2,046$ ) } \\
\hline Male & $50.29 \%$ & - & - \\
\hline Annual family income (unit: $1,000,000 \mathrm{KW}$ ) & $47.80(27.20)$ & 0 & 400 \\
\hline Parental education & $2.71 \quad(0.99)$ & 1 & 5 \\
\hline Parenting & $3.19 \quad(0.48)$ & 1.25 & 4.0 \\
\hline School adjustment & $2.90 \quad(0.39)$ & 1.30 & 4.0 \\
\hline Drinking & $6.80 \%$ & - & - \\
\hline Smoking & $6.26 \%$ & - & - \\
\hline \multicolumn{4}{|l|}{ Regional variable (Level 2, $N=92$ ) } \\
\hline Accommodation & $0.72 \quad(0.81)$ & 0.68 & 7.33 \\
\hline Saloon/Bar & $0.90 \quad(0.59)$ & 0.15 & 3.03 \\
\hline Smoking rate & $24.15 \quad(2.50)$ & 18.5 & 28.7 \\
\hline Drinking rate & $57.52 \quad(4.81)$ & 40.7 & 65.7 \\
\hline
\end{tabular}


(3) 음주율: 최근 1 년 동안 1 회 이상 음주한 사람의 백분율 $(\%)$

(4) 흡연율: 평생 5갑( 100 개비)이상 흡연한 사람으로서 현재 흡 연하는 사람(매일 피움 또는 가끔 피움)의 백분율(\%)

\section{2) 조절변수: 학교적응}

학교적응은 한국아동.청소년패널조사에서 측정한 것을 사용 하였다. "학교숙제를 빠뜨리지 않고 한다" 등의 학습활동, "학 교물건을 내 것처럼 소중히 사용한다” 등의 학교규칙, “우리반 아이들과 잘 어울린다" 등의 교우관계, "내년에도 지금 선생님 께서 담임선생님을 해 주셨으면 좋겠다" 등의 교사관계를 묻 는 각 5 문항씩 4 개의 하위요인으로 구성되어 있다. 각 문항은 4점 리커트형 척도로, 학습활동 5번, 교우관계 4번의 부정문항 을 제외한 나머지 긍정문항들을 역으로 환산하여 전혀 그렁지 않다 1점에서부터 매우 그렁다 4점까지, 점수가 높을수록 학 교적응을 잘하고 있다는 것을 의미한다. 본 연구에서의 학교 적응의 내적합치도(Cronbach's alpha)는 .751로 나타났다.

\section{3) 종속변수: 흡연경험, 음주경험}

청소년 흡연 및 음주행동으로 한국아동.청소년패널조사에서 측정한 변인을 사용하였다. 비행-연간 행동경험 횟수를 묻는 13 가지 질문 중 지난 일 년 동안 술마시기와 담배피우기에 대 한 행동경험 유무를 묻는 질문에 대한 응답으로, 술마시기와 담배피우기 경험이 없다면 없다에, 경험이 있다면 있다에 표 시를 하고 빈칸에 그 횟수를 써넣도록 한 것이다. 본 연구에서 는 흡연 및 음주경험이 없는 학생들은 ' 0 ', 경험이 있는 학생은 ‘'로 구분하여 이진형 변수로 사용하였다.

\section{4) 통제변수}

선행연구(Chung \& Joung, 2014; Hwang, 2010; Min, 2014; Shin $\& \mathrm{Jang}$, 2013)에서 밝혀진 청소년 행동에 영향을 주는 개인요 인 및 가정환경요인들을 통제변수로 설정하였다.

(1) 성별: 여자는 '0', 남자는 ' 1 '의 값으로 더미코딩

(2) 가구소득: 지난 1년 간 가구소득을 '만 원’ 단위로 기입한 금 액을 ‘백만 원' 단위로 변경하여 사용

(3) 부모학력: '부'와 ‘모' 중 최종학력이 높은 부모의 것을 사용 하였다. 중졸이하 $(=1)$, 고졸 $(=2)$, 전문대 졸 $(=3)$, 대학 졸 $(=4)$, 대 학원 졸 $(=5)$ 로 구분

(4) 부모양육: 한국아동.청소년패널조사의 가정환경요인에서
측정한 부모의 방임과 학대를 사용하였다. "다른 일(직장이나 바깥일)보다 나를 더 중요하게 생각하신다" 등의 방임, "내가 무언가 잘못했을 때 정도이상으로 심하게 혼내신다” 등의 학 대로 각 4문항씩 2개 하위요인으로 구성되어 있다. 각 문항은 4점 리커트형 척도로 점수가 높을수록 방임과 학대를 낮게 지 각함을 의미

\section{3. 자료분석}

본 연구는 지역사회 유해환경이 청소년 음주 및 흡연행동에 미치는 효과를 알아보고, 보호요인으로 학교적응의 조절효과 를 분석하였다. 이를 위해 개인(1수준) - 지역(2수준)유형의 다 층모형(multilevel model)을 적용한 로지스틱 회귀분석(logistic regression)을 실시하였다. 한국아동.청소년패널조사의 청소년 들은 시·군·구 단위 행정지역에 내포되어 있어 다층모형이 개 인-지역유형의 위계적 구조(hierarchical structure)를 활용한 분 석에 적합하다(Raudenbush \& Bryk, 2002). 분석을 위해 STATA 13의 xtmelogit command (StataCorp, TX)를 사용하였다.

일반회귀분석모델과 다층분석모델의 차이는 잔차항 (residual error term)의 특성에 있다. 일반회귀분석은 잔차항이 하나의 수준에서만 측정되지만, 다층모형에서는 위계적 수준 마다 하나씩 존재하게 된다. 본 연구에서는 청소년 개인(1수 준)의 잔차항뿐만 아니라, 같은 지역 내 학교에 재학 중인 청 소년들이 공유하는 시·군·구 단위 지역수준(2수준)의 잔차항 도 고려할 것이다. 이에 특정지역 학교에 재학 중인 청소년의 음주 및 흡연 여부는 고정효과와 개인수준과 지역수준의 분산 을 반영한 상.하위단위 각각에 대한 2 개의 무선효과로 측정된 다. 가능도비 검증(likelihood ratio test)을 통해 일반로지스틱모 델대비 다층모형로지스틱모델의 적합도를 제시하였다. 분석 결과로 로지스틱계수(B)와 승산비(Odds Ratio) 두 가지를 산 출하여 보고하였다.

\section{연구결과}

1. 지역사회 유해환경과 청소년의 음주경험과의 관 계에서 학교적응의 보호작용

먼저, 지역사회 유해환경과 청소년의 학교적응이 청소년 음 주행동에 미치는 효과를 살펴보기 위하여 성별, 부모학력, 가 구소득 그리고 부모양육을 통제한 상태에서 로지스틱 회귀 
분석을 실시하였다. 그 결과, 지역사회 유해환경 중 음주율 $(B$ $=0.08, p<.01, O R=1.08)$, 숙박업소 $(B=0.70, p<.05, O R=$ $2.00)$, 그리고 학교적응 $(B=-1.36, p<.001, O R=0.26)$ 에서 유 의한 결과가 나타났다. 즉, 학교가 위치한 지역사회 음주율이 높을수록, 또는 지역사회 숙박업소가 많을수록 청소년의 음주 경험 가능성이 높아진다는 것이다. 지역사회 유흥업소 수가 청소년 음주행동에 직접적으로 미치는 효과는 통계적으로 유 의하지 않았다. 반면, 청소년의 학교적응이 높을수록 음주경 험 가능성은 감소한다고 볼 수 있다.

다음은 지역사회 유해환경이 청소년 음주행동에 미치는 주 효과(main effect)가 유의한 변수를 중심으로, 주효과를 통제한 후 유해환경이 청소년 음주행동에 미치는 효과가 학교적응에 따라 달라지는지 상호작용효과를 분석하였다. Buis (2010)가 제 시한 승법 효과(multiplicative effect) 방법을 이용하여 비선형모 형에서의 주효과 및 상호작용항을 해석한 결과는 다음과 같다.

학교적응의 승산비는 $0.0004(B=-7.81, p<.05, O R=$
0.0004)로, 학교적응이 높아짐에 따라 청소년 음주경험의 승 산이 0.0004 배가 된다. 학교적응과 지역사회 음주율간 상호 작용도 유의 $(B=0.11, p<.05, O R=1.12)$ 하였다. 이는 음주율 이 높은 지역사회에서의 학교적응의 부적승산효과가 음주율 이 낮은 지역사회에서의 학교적응 효과의 1.12 배 수준임을 나 타낸다. 또한 지역사회 숙박업소의 승산비는 $136(B=4.91, p$ $<.001, O R=135.89)$ 으로, 지역사회 숙박업소가 1단위 높아짐 에 따라 청소년 음주경험의 승산은 136 배 증가한다는 것을 의 미한다. 학교적응과 지역사회 숙박업소간 상호작용도 유의하 여 $(B=-1.59, p<.05, O R=0.20)$ 지역사회 숙박업소 증가에 따 른 청소년 음주경험의 정적승산비가 학교적응이 높을 경우 대 비 학교적응이 낮을 경우 0.20 배 수준이었다.

이러한 지역사회 유해환경인 음주율과 숙박업소가 청소년 음주에 미치는 효과에서 학교적응의 보호작용을 구체적으로 살펴보기 위하여 그래프를 도출하였다. 연속변인으로 측정한 학교적응 변인에 대해 그래프를 용이하게 그리기 위해 simple

Table 2

Logistic Regression Predicting Drinking Experience for $9^{\text {th }}$ Grade

$(N=2,046)$

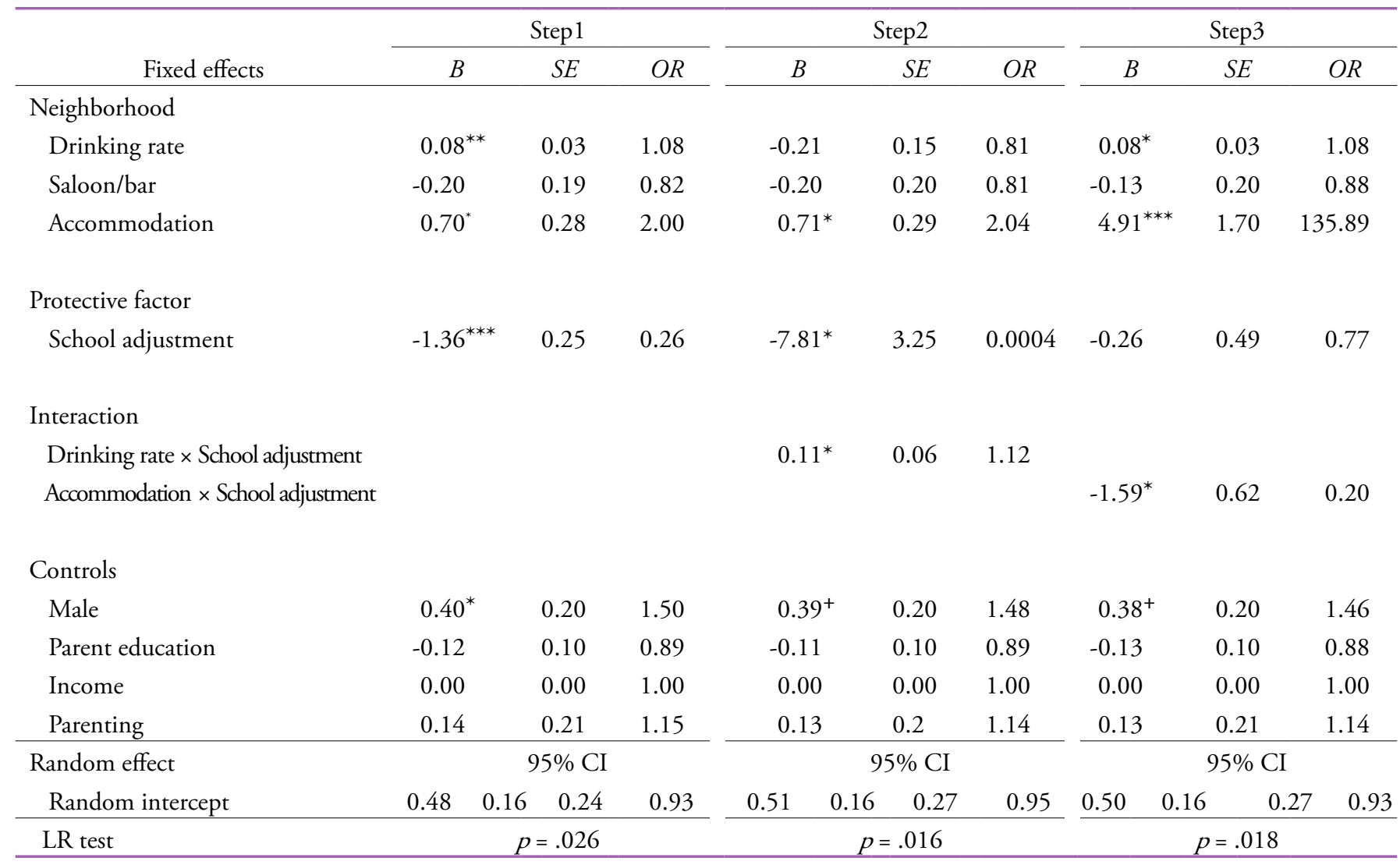

${ }^{+} p<.1{ }^{*} p<.05 .{ }^{* *} p<.01 .{ }^{* * *} p<.001$. 
slopes analysis (Aiken \& West, 1991)를 적용하여 학교적응이 높 은 집단 $(M+1 S D)$, 중간인 집단 $(M)$, 낮은 집단 $(M-1 S D)$ 을 설정 하였다. 먼저, Figure 1에서는, 거주 지역의 음주율이 높을수록 청소년들의 음주행동이 증가하는 경향이 있지만, 학교적응이 낮은 청소년들의 음주경험 확률이 더 급격하게 증가하는데 비 해 학교적응이 높은 청소년들의 음주경험 확률은 더 완만하게 증가하는 것으로 나타났다. 즉, 학교적응을 잘하는 청소년일 수록 지역사회 음주율이 청소년의 음주행동에 미치는 부정적 효과가 완충된다고 볼 수 있다.

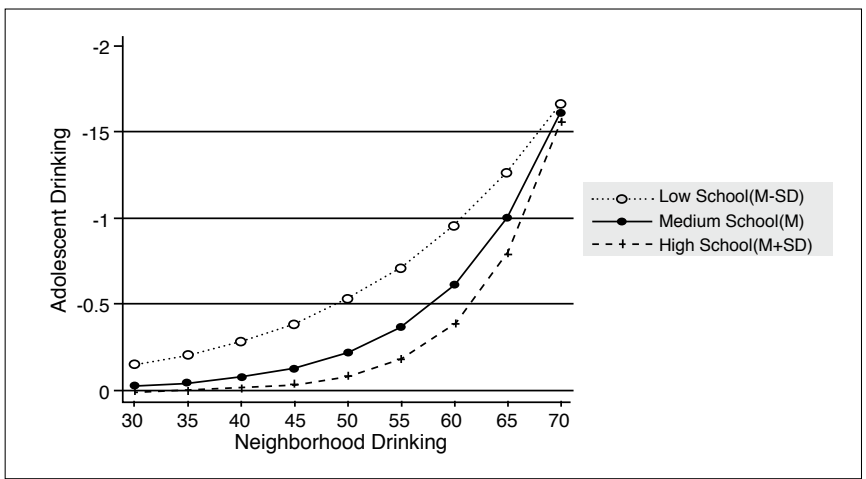

Figure 1. The moderating effect of school adjustment in the relationship between neighborhood drinking rate and adolescent drinking for $9^{\text {th }}$ graders

다음 Figure 2 를 살펴보면, 지역사회 숙박업소가 청소년 음 주에 미치는 부정적 효과가 학교적응이 낮은 청소년들에게서 는 큰 반면, 학교적응이 높은 청소년들에게는 나타나지 않았 다. 즉, 학교적응이 낮은 청소년의 경우 지역의 숙박업소가 많 을수록 청소년들의 음주경험 확률이 증가하지만, 학교적응을 잘하는 청소년들은 숙박업소와 같은 지역사회 유해환경의 영 향을 거의 받지 않는다고 해석할 수 있다.

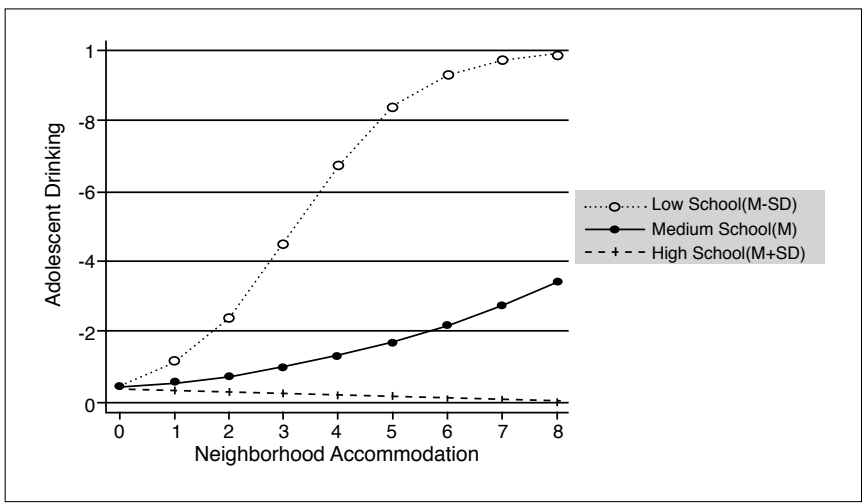

Figure 2. The moderating effect of school adjustment in the relationship between neighborhood accommodation and adolescent drinking for $9^{\text {th }}$ graders
2. 지역사회 유해환경과 청소년의 흡연행동과의 관 계에서 학교적응의 보호 작용

다음으로 지역사회 유해환경과 청소년의 학교적응이 청소년 흡연행동에 미치는 효과를 살펴보기 위하여 성별, 부모학력, 가 구소득 그리고 부모양육을 통제한 상태에서 로지스틱 회귀분 석을 실시하였다. 그 결과, 지역사회 유해환경 중 흡연율 $(B=$ $0.10, p<.05, O R=1.10)$ 에서 그리고 학교적응 $(B=-1.96, p<.001$, $O R=0.14)$ 에서 유의한 효과가 나타났다. 즉, 거주 지역 흡연율 이 높을수록 청소년 음주경험 확률이 증가하지만, 청소년의 학 교적응 수준이 높을수록 청소년 음주경험 가능성은 감소한다 고 볼 수 있다. 그러나 지역사회 유흥업소와 숙박업소 수가 청소 년 흡연행동에 미치는 효과는 통계적으로 유의하지 않았다.

다음은 지역사회 유해환경이 청소년 흡연행동에 미치는 주 효과(main effect)가 유의한 변수를 중심으로, 유해환경이 청소 년 흡연행동에 미치는 효과가 학교적응에 따라 달라지는지 확 인하기 위한 상호작용효과를 분석하였다. 그 결과, 지역사회 흡연율 $(B=0.66, p<.05, O R=1.93)$, 그리고 지역사회 흡연율 과 학교적응의 상호작용 $(B=-0.21, p<.05, O R=0.81)$ 이 유의 하게 나타났다. 즉, 청소년 흡연경험의 승산은 지역사회 흡연 율이 증가함에 따라 1.93 배 증가하며, 지역사회 흡연율 증가 에 따른 청소년 흡연경험의 정적 승산비가 학교적응이 높을 경우 대비 학교적응이 낮을 경우의 0.81 배로 나타났다.

Figure 3은 지역 흡연율과 청소년 흡연과의 관계에서 학교 적응의 보호작용을 구체적으로 살펴보기 위한 것이다. 지역사 회 흡연율이 청소년 흡연행동에 미치는 부정적 효과가 학교적 응이 낮은 청소년들에게서는 뚜렷하게 큰 반면, 학교적응이 높은 청소년들에게는 그 부정적 효과가 나타나지 않았다. 이 는 학교적응이 낮은 청소년의 경우 지역 흡연율이 높을 수록

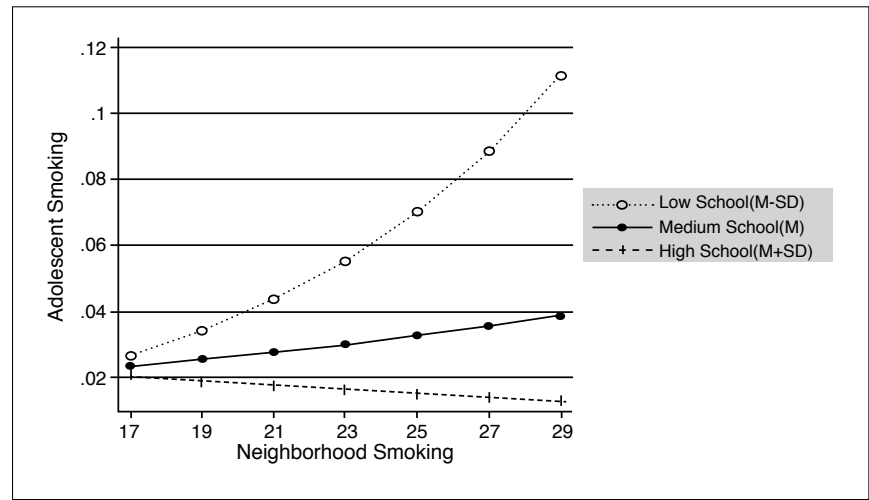

Figure 3. The moderating effect of school adjustment in the relationship between neighborhood smoking rate and adolescent smoking for $9^{\text {th }}$ graders 
Table 3

Logistic Regression Predicting Smoking Experience for $9^{\text {th }}$ Grade

$(N=2,046)$

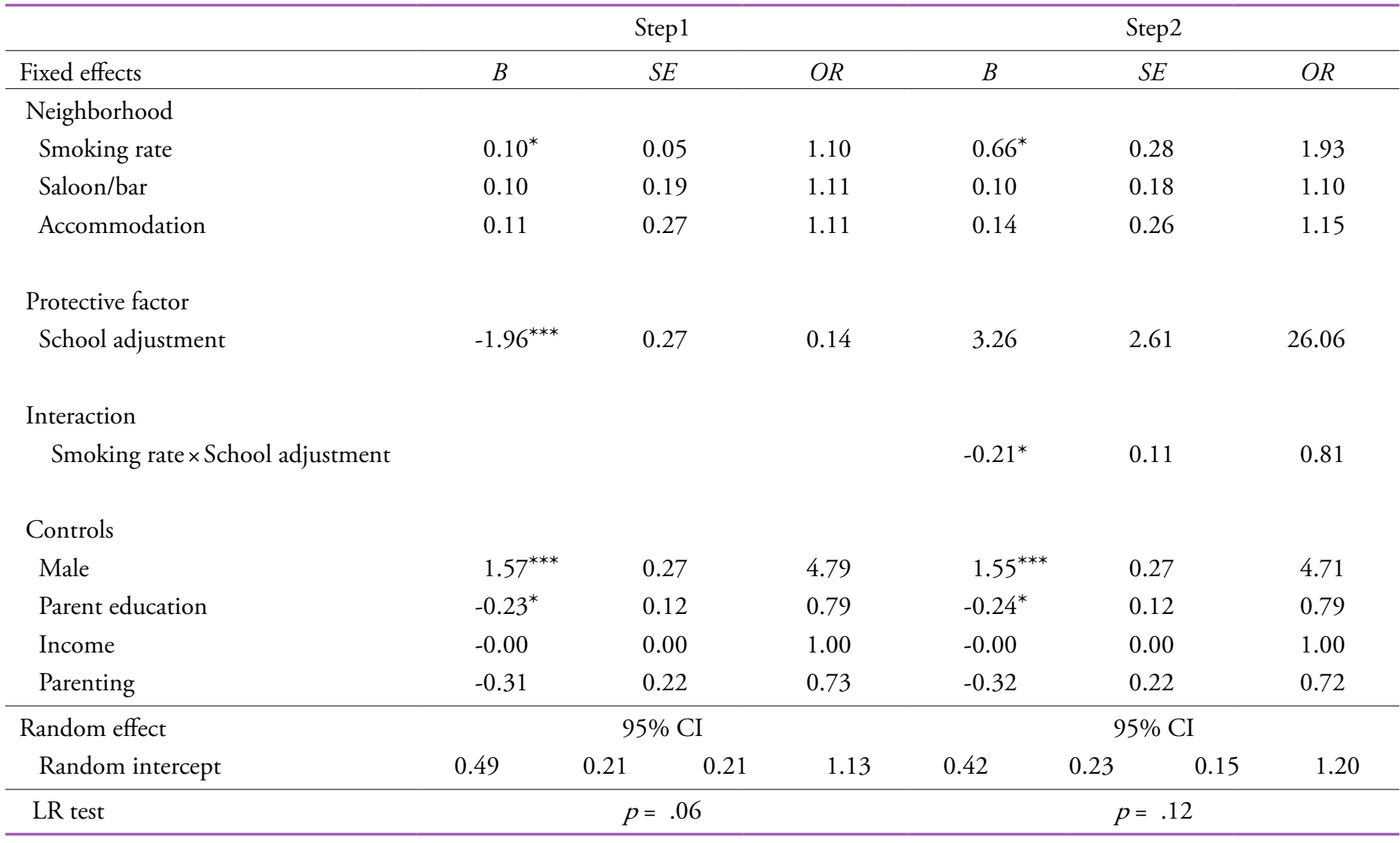

${ }^{*} p<.05 .{ }^{* * *} p<.001$.

청소년들의 흡연이 증가하지만, 학교적응을 잘하는 청소년들 은 지역 흡연율과 같은 지역사회 유해환경의 영향을 받지 않 는다고 해석할 수 있다.

\section{논의 및 결론}

우리나라 청소년의 음주 및 흡연행동이 심각한 사회현상인 가 운데 본 연구는 개입에 필요한 보호요인을 제안하기 위해 경험 적 연구를 시행하였다. 이를 위해 생태체계이론에 근거하여 청 소년 유해환경을 숙박업소, 유흥업소, 지역 음주율, 그리고 지 역 흡연율을 중심으로, 지역사회 유해환경이 청소년 행동에 미 치는 효과 검증과 보호요인으로써 청소년의 학교적응을 분석 하였다. 본 연구의 주요 결과와 그에 따른 논의는 다음과 같다.

먼저, 지역사회 유해환경 중, 음주율과 숙박업소가 청소년 음주에 미치는 부정적 효과는 유의하였다. 즉, 거주 지역 만 19세 이상 성인인구의 음주율이 높을수록, 그리고 거주 지역
에 숙박업소가 많을수록 청소년들의 음주행동은 증가하는 것 이다. 그러나 음주율과 숙박업소가 청소년들에게 미치는 부정 적 영향은 청소년의 학교적응에 의해 조절되었다. 이는 지역 사회 음주율이 높을수록, 숙박업소가 많을수록 청소년의 음주 행동은 증가하지만, 만약 청소년들이 교사 및 교우와 긍정적 관계를 맺고, 학습활동 및 학교생활에 흥미를 가지고 잘 적응 한다면 유해환경의 부정적 영향을 상쇄 시킬 수 있다는 가능 성을 제시한다.

본 연구에서 학교적응의 완충효과가 가장 강하게 나타난 것은, 지역사회 음주율과 청소년 음주행동 간의 관계였다. 일 상생활에서 무의식적으로 목격되는 음주행위들은 음주 모방 행위 등을 야기함으로써 청소년에게 해로운 영향을 미칠 수 있는 유해요인이다. 그러나 본 연구를 통해 유해환경의 청소 년 문제행동에 대한 해로운 영향을 막기 위한 제도적 접근 뿐 아니라 이를 완화시켜줄 수 있는 학교적응이라는 보호요인을 통한 청소년 적응 증진 방안의 중요성이 증명된 것이다. 즉, 음 주율이 높은 지역이라 하더라도 청소년기 적응의 지표로서, 
청소년들이 건강한 발달과업에 몰입할 수 있는 학교적응을 강 화할 수 있는 사회적, 제도적 노력을 통해 청소년의 음주행위 를 제지하거나 늦출 수 있는 방안을 권고해 볼 수 있을 것이다.

본 연구에서는 지역 내 모텔과 같은 숙박업소가 많을수록 청소년들의 음주행동이 부정적 영향을 크게 받았고, 특히 학 교적응이 낮은 청소년들에게는 숙박업소의 유해성이 더욱 강 하게 나타났다. 숙박업소는 청소년보호법에서 규정된 '청소년 고용이 금지'되는 시설이다. 즉, 청소년 고용은 불가능 하지만 출입이 가능하기 때문에, 청소년들이 이곳에서 친구들과 어울 려 술을 마시거나, 직.간접적 유해요인으로부터 영향을 받을 수 있다. 법적으로 청소년 고용이 불가능함에도 불구하고 청 소년유해환경접촉 종합실태조사(MOGEF, 2014)에 따르면 청 소년 고용 금지업소에서의 아르바이트 경험이 위기청소년들 의 경우 $19.7 \%$ 로 높았다. 본 연구의 분석결과와 연결 지어 볼 때, 숙박업소에서의 출입 및 고용으로 인한 유해요인의 효과 가 학교적응이 높은 청소년들에게는 크지 않지만, 위기청소년 과 같은 학교적응에 어려움이 있는 청소년에게는 직접적으로 해로울 수 있음을 보여준다.

다음으로 청소년 흡연에 대한 지역사회 유해환경 가운 데, 흡연율의 부정적 효과가 유의하였다. 즉, 거주 지역 만 19 세 이상 성인인구 중 현재 흡연하고 있는 사람이 많을수록 청 소년들의 흡연행동은 증가하는 것이다. 이는 전체 응답자의 $30.7 \%$ 가 최근 일주일 동안 가정에서 간접흡연에 노출된 경험 이 있다고 응답한 조사결과에서처럼(MOGEF, 2014), 많은 청 소년들이 일상생활에서 흡연에 노출되어 있다. 현재 사회적으 로 담뱃값 인상과 함께, 흡연 금지구역이 확대되고, 정부로부 터 다양한 금연서비스가 제공되고 있지만, 특히 가정과 같은 공공장소가 아닌 곳에서 간접흡연에 대한 인식개선과 교육이 필요하다는 것을 시사하는 결과이다. 그러나 이러한 지역 흡 연율의 유해성은 청소년들의 학교적응에 의해 조절되었다. 청 소년들이 교사 및 교우와 긍정적 관계를 갖지 못하고, 학교생 활에 잘 적응하지 못한다면 지역사회 흡연율의 부정적 영향 을 크게 받지만, 학교적응을 잘 한다면, 청소년 흡연에 대한 지 역 흡연율의 부정적 영향은 거의 없다고 볼 수 있다. 이는 학교 에 대한 만족, 급우의 지지, 학업성취와 같은 학교요인이 가정 환경 요인보다 청소년 위해행동에 더 두드러지는 효과를 가진 다는 선행연구를 통해서도 지지된다(Lazzeri et al., 2014). 결국, 청소년기는 아동기에 비해 지역사회와의 경험 및 접촉기회가 더 증가하는 시기로써(Aber et al., 1997) 그만큼 지역사회 유해 환경의 영향에 더 취약할 수밖에 없다. 따라서 청소년의 건강 한 성장을 위해 지역의 유해환경에 대한 직접적인 정책적 개
입이 중요할 것이다. 그러나 앞서 연구의 필요성에서도 밝혔 듯이 청소년 유해환경을 우리 사회에서 완전히 제거한다는 것 은 현실적으로 불가능하다(Han \& Kim, 2012). 따라서 청소년 의 긍정적 발달을 위한 보호요인의 촉진을 통해 유해환경의 부정적 영향을 완충하는 것이 필수적이다. 이러한 측면에서 본 연구에서 확인된 학교적응은 청소년 스스로 외부의 부정적 환경으로부터 내재적 보호능력을 향상시킬 수 있는 강력한 보 호요인일 것이다. 긍정적인 학교적응은 청소년기의 발달과업 이자, 청소년 건강의 지표로써 음주 및 흡연을 포함한 다양한 청소년 비행의 대표적인 보호요인이다(Han, 2008; Hawkins et al., 1992; Lazzeri et al., 2014; Lee \& Lee, 2008). 결국, 높은 학교 적응성 및 학교와의 긍정적인 유대관계를 통하여 유해환경에 대해 취약성을 보이는 청소년에 대한 잠재적 악영향으로부터 보호할 수 있을 것이다.

한편, 학년이 높아짐에 따라 학교적응은 감소하는 경향이 있다(Lee \& Cho, 2010). 특히 초등학교 6학년에서 중학교 1학 년처럼 상급학교로 진학하는 과도기에 그 감소의 폭이 가장 크다는 것이다. 본 연구의 대상인 중학교 3 학년도 상급학교 진 학에 대한 스트레스가 큰 시기로, 학교적응 감소의 가능성이 있다. Eccles (1999)는 청소년기는 가족으로부터의 독립성 추 구와 발달적.사회적 변화를 경험하는 과도기로서, 학교, 가정, 그리고 지역사회 프로그램들이 이 시기의 발달적 특성을 도울 수 있도록 만들어져야함을 강조하였다. 만약 그러한 프로그 램들이 청소년들의 요구에 적절히 대응하지 못한다면, 스스로 에 대한 자신감을 잃을 수 있고 부정적 행동에 빠질 가능성을 경고하였다. 결국, 다양한 변화를 경험하는 과도기로써 이 시 기 청소년들은 유해환경에 취약하고, 학교적응 또한 불안정할 수 있다. 따라서 가정, 학교 그리고 지역사회가 청소년의 발달 적 요구에 적절하고 체계적으로 잘 조직화된 학교적응 프로그 램들을 개발, 수행한다면 음주, 흡연과 같은 부정적 행동이 더 심각한 문제로 이어질 가능성을 막고 청소년의 건강한 발달을 도울 수 있을 것이다.

특별히 본 연구에서 유흥업소가 청소년 음주 및 흡연에 미 치는 효과가 유의하지 않았다. 이러한 결과에 대해 다음과 같 이 생각해 볼 수 있다. 단란주점 및 유흥주점과 같은 유흥업소 는 청소년보호법에서 구분하고 있는 청소년 출입·고용 금지업 소이다. 따라서 지역의 음주율 및 흡연율처럼 청소년 음주 및 흡연행동에 직접적 효과를 보이기보다는 제 3 요인을 통한 간 접효과의 가능성을 예측해 볼 수 있다. 이는 지역단위 통계자 료를 사용하여 지역사회의 구조적 특성이 청소년 발달에 미 치는 영향에 관한 연구를 통해서도 확인할 수 있다(Plunkett, 
Abarca-Mortensen, Behnke, \& Sands, 2007). 즉, Plunkett 등 (2007)의 연구에서는 지역 환경은 거주 지역에 대한 청소년 의 인식을 통해 간접적으로 청소년 발달에 영향을 미쳤다. 이 에 종합적인 국가통계자료를 사용한 지역 환경과 청소년 발달 간의 관계는 직접적이기 보다는 간접적인 관련성이 더 명확 할 수 있음을 제안하였다. 또 다른 연구에서도 지역사회는 부 모요인에는 영향을 미쳤으나 청소년의 지위비행과는 직접적 인 관계가 나타나지 않았다(Yun, 2010). 따라서 추후 연구에서 는 지역 환경과 청소년 행동 간에, 또래나 가정요인 또는 거주 지역에 대한 청소년의 인식과 같은 요인들을 통한 효과검증을 시도할 필요가 있겠다.

지금까지 본 연구결과를 통한 후속연구 발전 가능성을 제시 하면 다음과 같다. 첫째, '유해환경'의 종류는 다양하며, 그 해 로움이 청소년에게 미치는 경로 또한 다양할 것이다. 본 연구 에서는 법적조항에서 정의하는 유해업소만을 분석대상으로 하였다. 추후 연구에서는 지역사회 범죄환경, 교육환경 등, 유 해환경의 구분에 따라 청소년들에게 미치는 직.간접적 영향과 그 경로에 대한 연구가 이루어져야 한다. 둘째, 본 연구에서는 청소년 위해행동에 대한 보호요인으로 학교적응에만 초점을 두었다. 그러나 학교적응의 조절효과가 통계적으로 유의하였 다는 결과만으로, 학습부진 및 학업포기로 이어지는 학교부적 응이 청소년의 음주 및 흡연행동까지 연결된다는 근거와 학교 적응력 향상만을 청소년의 음주 및 흡연행동에 대한 예방 전략 으로 강하게 피력하기에는 다소 제약이 있을 수 있다. 따라서 청소년들의 심리적 특성 또한 고려한 대안과 함께 향후 청소년 의 음주 및 흡연행동을 예방하고 긍정적 발달을 향상시키는 다 양한 보호요인 탐색을 위한 후속연구가 필요할 것이다.

마지막으로 본 연구의 의의는 다음과 같다. 본 연구는 전국 청소년 조사자료와 시·군·구 교육·행정 자료를 병합한 실증적 연구를 통해 개인, 가족수준에서 확장된 거시체계로써 지역사 회 유해환경이 청소년에게 미치는 효과를 검증하였다. 또한 청소년에 대한 유해환경의 악영향을 상쇄시킬 개입 방안을 제 시하였다. 청소년보호법 등을 기반으로 한 청소년 유해환경에 대한 사법.행정적 조치가 강화되었지만, 이를 남용하는 유해 업소 및 매체는 진화하고 새로이 등장하고 있어 청소년 유해 환경을 완전히 제거한다는 것은 현실적으로 불가능하다(Han $\& \mathrm{Kim}, 2012)$. 따라서 사법.행정적 접근에 의존하지 않고 청소 년 스스로 유해환경의 부정적 영향을 상쇄시킬 수 있는 미시 체계내의 보호요인 파악은 중요하다. 본 연구의 결과를 토대 로 청소년의 학교적응 강화에 초점을 둔 개입 방안을 통해 내. 외적 스트레스에 대한 청소년의 내재적 보호능력을 향상시키
고 긍정적 발달을 유도하는 등 유해환경의 부정적 영향을 완 충해주는 효과를 기대할 수 있을 것이다.

\section{Acknowledgements}

This study was supported by the 2014 National Research Foundation of Korea (NRF-2014S1A5A8019142).

\section{Notes}

This article was presented as a poster at the Hong Kong International Conference on Social Science in 2015.

\section{Conflict of Interest}

No potential conflict of interest relevant to this article was reported.

\section{References}

Aber, J. L., Gephart, M. A., Brooks-Gunn, J. B., \& Connell, J. P. (1997). Development in context: Implications for studying neighborhood effects. In J. B. Brooks-Gunn, G. J. Duncan, \& J. L. Aber (Eds.), Neighborhood poverty: Context and consequences for children (Vol. 1, pp. 44-61). New York, NY: Russell Sage Foundation.

Aiken, L. S., \& West, S. G. (1991). Multiple regression: Testing and interpreting interactions. Thousand Oaks, CA: Sage Publications.

Babbin, S. F., Velicer, W. F., Paiva, A. L., Brick, L. A. D., \& Redding, C. A. (2015). Replicating cluster subtypes for the prevention of adolescent smoking and alcohol use. Addictive Behaviors, 40, 57-65. doi: 10.1016/j.addbeh.2014.09.001

Bronfenbrenner, U. (1979). The ecology of human development: Experiments by nature and design. Cambridge, MA: Harvard University Press.

Buis, M. L. (2010). Stata tip 87: Interpretation of interactions in non-linear models. The Stata Journal, 10(2), 305-308.

Chung, S. S., \& Joung, K. H. (2014). Risk factors for current smoking among american and South Korean adolescents, 2005-2011. Journal of Nursing Scholarship, 46(6), 408-415. doi: $10.1111 /$ jnu. 12099

Deković, M. (1999). Risk and protective factors in the development of problem behavior during adolescence. 
Journal of Youth and Adolescence, 28(6), 667-685. doi: 10.1023/A:1021635516758

Eccles, J. S. (1999). The development of children ages 6 to 14 . The Future of Children, 9(2), 30-44. doi: 10.2307/1602703

Erickson, K. G., Crosnoe, R., \& Dornbusch, S. (2000). A social process model of adolescent deviance: Combining social control and differential association perspectives. Journal of Youth and Adolescence, 29(4), 395-425. doi: 10.1023/ A: 1005163724952

Han, S. C. (2008). Exploration on risk and protective factors of adolescent runaway. Korean Psychological Journal of Culture and Social Issues, 14(1), 273-298.

Han, S. C., \& Kim, P. H. (2012). Adolescent's self-improvement methods of harmful environment: Focus on resilience. Forum for Youth Culture, 31, 121-145.

Han, Y., Kim, H., \& Ma, J. (2015). School bonds and the onset of substance use among Korean youth: An examination of social control theory. International Journal of Environmental Research and Public Health, 12(3), 2923-2940. doi: 10.3390/ijerph120302923

Hawkins, J. D., Catalano, R. F., \& Miller, J. Y. (1992). Risk and protective factors for alcohol and other drug problems in adolescence and early adulthood: Implications for substance abuse prevention. Psychological Bulletin, 112(1), 64-105. doi: 10.1037/0033-2909.112.1.64

Hong, J. S., Lee, N. Y., Grogan-Kaylor, A., \& Huang, H. (2011). Alcohol and tobacco use among South Korean adolescents: An ecological review of the literature. Children and Youth Services Review, 33(7), 1120-1126. doi: 10.1016/ j.childyouth.2011.02.004

Hwang, S. H. (2010). Parental and peer factors influence on adolescents' drinking and smoking behaviors. Korean Association of Health and Medical Sociology, 27, 81-103.

Hwang, S. H. (2012). A study of interaction theory on adolescents' status offenses using logistic regression analyses. Korean Journal of Youth Studies, 19(10), 23-43.

Jung, H. J. (2015, May 7). Drink, Korea! The heaven of drinking with IU. Pressian. Retrieved from http://www.pressian.com/ news/article.html?no=126239

Kang, H. J., \& Nho, C. R. (2012). The effect of area on adolescents' self-concept. Studies on Korean Youth, 23(4), 101-129.

Kim, J. K., \& Kim, G. H. (2013). Factor affecting drinking and drinking frequency among Korean youth. Korean Journal of Youth Studies, 20(2), 317-347.

Kim, S. W. (2009). A study of neighborhood effects on adolescent psychological adjustment: Using multilevel growth model. Journal of the Korean Society of Child Welfare, 28, 101-135.

Kim, Y. H., Ju, D. B., \& Lim, S. T. (2008). The development of classification system of harmful facility for youth and the analysis of current conditions on new and various harmful facility for youth. Journal of the Korea Institute of Youth Facility and Environment, 6(4), 77-89.

Kim, Y. I., \& Cha, J. I. (2007). Youth's contacting and spreading channels of harmful facilities' risk factors. Korean Journal of Youth Studies, 14(2), 187-211.

Kim, Y. I., \& Yoo, J. I. (2006). A study on the risk factors of youth harmful facilities. Journal of the Korea Institute of Youth Facility and Environment, 4(3), 39-59.

Kim, Y. S., \& Jeong, B. R. (2010). An analysis of articles related to smoking and smoking cessation of Korean adolescents. Journal Korean Academy Community Health Nursing, 21(1), 53-62.

Korea Centers of Disease Control and Prevention. (2014). The 10th Korea Youth Health Behavior Web-based Survey (Report No. 11-1460736-000038-10). Retrieved from http://yhs. cdc.go.kr/new $/$ index.asp?c=pds \&s $=1 \& \mathrm{gbn}=$ viewok\&sp $=\& s$ $\mathrm{w}=\& \mathrm{ps}=10 \& \mathrm{gp}=1 \& \mathrm{ix}=8$

Lazzeri, G., Azzolini, E., Pammolli, A., Simi, R., Meoni, V., \& Giacchi, M. V. (2014). Factors associated with unhealthy behaviours and health outcomes: A cross-sectional study among tuscan adolescents (Italy). International Journal for Equity in Health, 13(1), 81-99. doi: 10.1186/s12939-0140083-5

Lee, H. J., \& Cho, Y. J. (2010). The exploratory study of longitudinal changes and variables predicting school adjustment. Korean Journal of Youth Studies, 17(2), 253278.

Lee, J. H., \& Lee, S. C. (2008). The interaction between the resilience factor of juvenile delinquency and environment factor effects on the risk factor in juvenile delinquency. Korean Journal of Youth Studies, 15(1), 407-430.

Lee, K. M. (2005). A study of middle-school students' school adjustment constructs. Korean Journal of Counseling and Psychology, 17(2), 383-398.

Lee, M. S. (1996). Regulation intensity of detrimental environment for youth. (Research report No. 96-05). Sejong, Korea: Korea Institute for Youth Development.

Min, W. H. (2014). Physical aggression on growth trajectories of the adolescent drinking and smoking: Moderating effects of peer influences. Korean Journal of Youth Welfare, 16(1), 283304.

Ministry of Gender Equality \& Family. (2014). 2014 Comprehensive Survey on Youth Harmful Environment (Report No. 111383000-000607-11). Retrieved from www.mogef.go.kr/ files/directDownload/c.pdf

Plunkett, S. W., Abarca-Mortensen, S., Behnke, A. O., \& Sands, T. (2007). Neighborhood structural qualities, adolescents' perceptions of neighborhoods, and Latino youth development. Hispanic Journal of Behavioral Sciences, 29(1), 
19-34. doi: 10.1177/0739986306295038

Raudenbush, S. W., \& Bryk, A. S. (2002). Hierarchical linear models: Applications and data analysis methods (2nd ed., Vol. 1). Thousand Oaks, CA: Sage Publications.

Rhee, D., Yun, S. C., \& Khang, Y. H. (2007). Co-occurrence of problem behaviors in South Korean adolescents: Findings from Korea Youth Panel Survey. The Journal of Adolescent Health, 40(2), 195-197. doi: 10.1016/ j.jadohealth.2006.08.007

Sampson, R. J., Morenoff, J. D., \& Gannon-Rowley, T. (2002). Assessing "neighborhood effects": Social processes and new directions in research. Annual Review of Sociology, 28, 443478. doi: 10.1146/annurev.soc.28.110601.141114

Shin, S. Y., \& Jang, H. S. (2013). Influence of parents' self-control and parenting behavior on the juvenile delinquency: Comparison of self-control between father and mother. Journal of Korean Criminological Association, 7(2), 3-33.

Stata Statistical Software (Version 13) [Computer software]. College Station, TX: StataCorp LP.

Steinberg, L. (2005). Cognitive and affective development in adolescence. Trends in Cognitive Sciences, 9(2), 69-74. doi: $10.1016 /$ j.tics.2004.12.005

Yoo, J. I. (2007). A study of improving counterplan of the detrimental environments according the youth harmful facilities \& risk factors in Pyeongtaek city. Korea Institute of Youth Facility \& Envir onment, 5(2), 77-86.

Yun, W. S. (2010). The impacts of communities' ecological characteristics on status delinquency and parenting behaviors. Korean Criminological Review, 81, 175-202.

\section{ORCID}

Shinah Kim http://orcid.org/0000-0002-2922-6500

Yoonsun Han http://orcid.org/0000-0002-1108-0275

Received October 30, 2015

Revision received February 19, 2016

Accepted February 25, 2016 